\title{
Variations of cadmium concentrations and cadmium isotopes in Mytilus from North Atlantic and Baltic Sea
}

\section{JESPER ALLAN FREDERIKSEN AND ROBERT FREI}

University of Copenhagen

Presenting Author: jaf@ign.ku.dk

Cadmium (Cd) is an essential trace-micronutrient, and its distribution in modern ocean seawater columns is similar to major nutrients. Cadmium isotopes and cadmium concentrations $[\mathrm{Cd}]$ in seawater are useful proxies for reconstruction of ocean circulation, and for tracing the distribution of seawater nutrients from deep waters to surface waters. The preferred uptake of light $\mathrm{Cd}$ isotopes by phytoplankton renders surface seawater positively fractionated, and therefore the stable $\mathrm{Cd}$ isotopes and $\mathrm{Cd}$ concentrations are regarded as an indicator for primary producers in the photic zone. Herein we attempt to analyze $\mathrm{Cd}$ isotopes and [Cd] in filter-feeding Mytilus edulis in order to quantify, if at all, an isotopic effect recorded in their shell that can be attributed either to biological fractionation during uptake into the living organism and/or to fractionation in the shell forming process. Our preliminary test results from living mussel organism of Mytilus edulis from Danish waters of the Baltic Sea show [Cd] of $11-53 \mathrm{ppb}$ and positively fractionated $\delta^{114} \mathrm{Cd}$ values $>1.7 \%$, and a negative offset in [Cd] of $\sim 30 \%$ and $\delta^{114} \mathrm{Cd}$ of $\sim 1.1 \%$ in their respective carbonate shells. Multiple analyses of Mytilus shells from the Baltic Sea yielded [Cd] of 2-42 ppb and an average $\mathrm{Cd}$ isotope signature of $-0.18 \% \pm 0.12(2 \mathrm{SD}, \mathrm{n}=10)$ with variations from -0.72 to $+1.16 \%$. Specimen analyzed from the North Atlantic yielded [Cd] of $8-30 \mathrm{ppb}$ and an average $\mathrm{Cd}$ isotope signature of $-0.43 \% \pm 0.08(2 \mathrm{SD}, \mathrm{n}=5)$, with variations from -1.64 to $+0.19 \%$. Compared to [Cd] of $\sim 3 \mathrm{ppb}$ and $\delta^{114} \mathrm{Cd}$ of $\sim 0.64 \pm 0.14 \%$ characterizing North Atlantic Surface Seawater [1], our results point to a $\mathrm{Cd}$ isotope fractionation and enrichment in [Cd] during uptake of dissolved $\mathrm{Cd}$ from seawater into the living organism. This process favors the uptake of isotopically heavier $\mathrm{Cd}$ into the living mussel and shell, and would be in contrast to uptake of isotopically light dissolved $\mathrm{Cd}$ into phytoplankton. Additional measurements of Mytilus specimen from other marine environments are necessary to confirm this trend.

1. Ripperger, S., et al., 2007. Earth and Planetary Science Letters, 261(3): p. 670-684. 